\title{
Gebelik ile ilişkili Osteoporoz: Beş Yıl Takipli Bir Olgu Sunumu
}

\author{
Pregnancy Associated Osteoporosis: A Case Report with 5-Year Follow-up \\ Beyhan Eren, Özün Bayındır*, Gülseren Akyüz** \\ Mersin Devlet Hastanesi, Fizik Tedavi ve Rehabilitasyon Kliniği, Mersin, Türkiye \\ *Siirt Devlet Hastanesi, Fizik Tedavi ve Rehabilitasyon Kliniği, Siirt, Türkiye \\ **Marmara Üniversitesi Tıp Fakültesi, Fiziksel Tıp ve Rehabilitasyon Anabilim Dalı, İstanbul, Türkiye
}

\section{Özet}

Gebelik ile ilişkili osteoporoz (GiO) kadınları gebeliğin son üç ayında veya doğumdan sonra etkileyebilen nadir görülen bir klinik durumdur. GiO’nun prevelansı, nedeni, risk faktörleri, prognozu ile ilgili çok az şey bilinmektedir. Bir veya daha fazla vertebral kırığa, şiddetli, uzun süren sırt ağrısına ve boyda kısalmaya neden olabilir. Bu olgu sunumunda doğumdan bir ay sonra başlayan ciddi sırt ağrısı olan, multipl vertebral kırıklı 32 yaşındaki GiO tanılı hasta bildirilmektedir. Özgeçmişinde gecikmiş menarş, diyetle düşük kalsiyum alımı mevcuttu. Radyolojik incelemelerde 8. torakal vertebrada kompresyon fraktürü, 11. ve 12. torakal vertebralarda ve lomber omurgada kamalaşma görüldü. Kemik mineral yoğunluğu (KMY) ölçümünde total lomber bölge T-skoru ve Z-skoru -2,8, femur boynu T-skoru ve Z-skoru sırasıyla -1,2 ve -1,1 idi. Hafif alkalen fosfataz yüksekliği ve 25-hidroksi vitamin D düşüklüğü dışında laboratuvar incelemelerinde anormallik saptanmadı. Doğumdan üç ay sonra ağrıyı azaltmak amacıyla T8 kifoplasti uygulandı. Beş yıl takip boyunca tedavide vitamin D3, kalsiyum, kalsitonin, bisfosfonat, GABA anologları, analjezikler, fizik tedavi ajanları, kuru iğneleme kullanıldı. Tüm tedavi yöntemleri ile hastanın sırt ağrısı anlamlı derecede geriledi. On puanlık görsel analog skalaya (GAS) göre ağrı skoru 10'dan 3'e düştü, ancak 5 yıl takip boyunca kifoplasti çevresindeki lokalize ağrı hafif derecede (GAS skoru 3) de olsa devam etti. Takip süresi boyunca yeni kırık saptanmadı ve omurga KMY'sinde belirgin düzelme gözlendi. Hastanın günlük yaşam aktivitelerine katılımı arttı. Gebeliğin son üç ayında veya erken postpartum dönemde sırt ağıısı gelişen hastada ayıııı tanıda GiO düşünülmeli ve hastanın iyilik hali için uzun dönem destek planlanmalıdır. (Türk Osteoporoz Dergisi 2014;20: 36-40)

Anahtar Kelimeler: Gebelik ile ilişkili osteoporoz, vertebral kırık, tedavi

\section{Summary}

Pregnancy associated osteoporosis (PAO) is a rare clinical condition that may affect women during third trimester of pregnancy or after delivery. Little is known about the prevalence, cause, risk factors and prognosis of PAO. It can cause severe, prolonged back pain with one or more vertebral fractures and height loss. Herein we report a case of PAO in a 32 year-old female who presented with severe back pain with multiple vertebral fractures started 1 month after delivery. There were delayed menarche and low dietary calcium intake in history. The radiological examinations have shown compression fracture of $8^{\text {th }}$ thoracic vertebra and wedging of $11^{\text {th }}$ and $12^{\text {th }}$ thoracic vertebras and whole lumbar spine. In the bone mineral density (BMD) testing, total lumbar spine T-score and Z-score were -2,8 and femoral neck T-score and Z-score were -1,2 and -1,1 respectively. There were no abnormalities in laboratory findings except mild alkaline phosphatase elevation and low 25-hydroxy vitamin D level. Three months after delivery for pain reduction T8 kyphoplasty was applied. Along 5-year follow up vitamin D3, calcium, calcitonin, bisphosphonate, GABA anologs, analgesics, physical agents, dry needling were used for treatment. Back pain improved with all kinds of treatments significantly (On the 10-point visual analog scale (VAS) pain scores decreased from 10 to 3). The patient had continued pain in the operated area with decreased intensity (VAS score of 3) along 5-year follow up. There were no new fractures and marked recovery of spine BMD was observed during the same period. Activities of daily living improved permenantly. When back pain occurs in a patient at last trimester of pregnancy or early postpartum period, PAO should be considered in differential diagnosis and long term support should be planned for patient's well being. (Turkish Journal of Osteoporosis 2014;20: 36-40)

Key words: Pregnancy associated osteoporosis, vertebral fracture, management 


\section{Giriş}

Kadınlarda sıkça rastlanılan osteoporozun (OP) aksine gebelik ile ilişkili osteoporoz (GiO) nadir görülen bir klinik tablodur. GiO'nun etiyolojisi ve patofizyolojisi tam olarak bilinmemektedir (1). Gebeliğin bir sonucu olarak mı geliştiği yoksa gebelikle rastlantısal olarak mı birlikte görüldüğü halen aydınlatılamamıştır. Fetal iskeletin mineralizasyonu ve maternal plazmanın genişlemesi maternal kalsiyum ihtiyacını arttırmaktadır. Kalsiyum intiyacı kalsiyumun barsaktan emiliminin arttırılması, böbrekten atılımının azaltılması ve maternal kemikten kalsiyum mobilizasyonu ile sağlanmaktadır. Hormonal değişiklikler, kilo artışı, aktivite kısıtlanmasına neden olabilen gebelik komplikasyonları, ilaç kullanımı maternal kemik sağlığını etkilemektedir (2). Gebelik ve laktasyon döneminde kemik ve mineral metabolizmasındaki değişiklikler fetüse yeterli kalsiyum geçişine izin vermektedir. Dolayısıyla gebelik ve emzirme döneminde görülen \%3-\%6'lık kemik kaybının ve omurga kırıklarının GiO'dan kaynaklanabileceği varsayılmaktadır (1).

Gebelik ile ilişkili OP sıklıkla ilk gebelikte görülür ve genellikle tekrarlayıcı değildir. Tanı konulurken gebelik sırasında ağrı ve kırıklara neden olabilen ikincil osteoporoz nedenleri, geçici osteoporoz, osteonekroz, simfiz pubis disfonksiyonu dışlanmalıdır $(3,4)$. Şu ana kadar GiO tedavisi ile ilgili herhangi bir kılavuz bulunmadığı gibi herhangi bir ortak görüş de sağlanabilmiş değildir. Bu nedenle tedavi planının hastaya göre belirlenmesi gerekmektedir. Gebeliğin son 3 ayında veya erken postpartum dönemde sırt, bel ağrısı yakınması ile başvuran kadınlarda ayırıcı tanıda GiO düşünülmelidir (1).

\section{Olgu}

Daha önce bilinen bir hastalığı olmayan, primigravid 32 yaşındaki hastanın gebeliğinin son ayında hafif düzeyde bel ağrısı başlamış. Kasım 2007'de vajinal yolla doğurduktan bir ay sonra hafif travma (elektrik süpürgesini kaldırma) sonrası ani başlangıçlı, çok şiddetli sırt ağrısı gelişmiş. Günlük yaşam aktivitelerini kısıtlayacak derecede olan sırt ağrısının yanı sıra halsizlik ve kilo kaybı (1 ayda 4-5 kilo), sırtta ağrılı bölgede uyuşma, batma yakınmaları da varmış. Dış merkezde doktora başvurduğunda miyalji tanısı ile verilen analjezik tedaviden fayda görmemiş. Hasta doğumdan dört ay sonra (Mart 2008) devam eden ağrıları nedeniyle hastanemizin acil polikliniğine başvurmuş. Ortopedi ve Travmatoloji Kliniği'nde Nisan 2008'de T8 ve T11 osteoporotik çökme kırıkları tanısı ile T8 kifoplasti uygulanmış. Postoperatif birinci gün mobilize olan hasta dört ay hiperekstansiyon ortezi kullanmıs. Operasyon sonrası hastaya gabapentin $1800 \mathrm{mg} / \mathrm{g}$, tramadol 200 mg/g, kalsiyum 1200 mg/g, vitamin D3 800 IU/g, steroid olmayan antiinflamatuvar ilaçlar başlanmış. Ek olarak depresif ruh hali nedeniyle amitriptilin $25 \mathrm{mg}$ verilmiş. Temmuz 2008'de OP etyolojisinin araştırıması ve ağrı tedavisi için polikliniğimize yönlendirilen hasta FTR servisine interne edildi. Özgeçmişinde sekonder OP düşündürecek (sigara ve alkol kullanımı, adet düzensizliği, östrojen yetersizliği, hafif travma sonucu geçirilmiş kırık, romatoid artrit, hipogonadizm, ooforektomi, erken menopoz, klomifen ile infertilite tedavisi, tip 1 osteojenezis imperfekta, gluten enteropatisi, kortikosteroid kullanımı, heparin kullanımı, anoreksiya nevroza, kemoterapi, kronik obstruktif akciğer hastalığı, diabetus mellitus, hipotiroidi, hipertiroidi, kronik karaciğer hastalığı, uzun dönem immobilizasyon) hastalık ya da ilaç kullanımı öyküsü mevcut değildi. Gecikmiş menarş (17 yaş) ve multinodüler guatr tanısı olan hasta 11 yıl önce apendektomi geçirmiş. Hastaya multinodüler guatr tanısı 2005 yılında konulmuş, ardından 2-3 ay süreli tiroid hormon tedavisi verilmiş. Hasta operasyon önerisini gebelik planladığından kabul etmemiş. Takiplerinde tiroid fonksiyon testlerinde anormallik, nodül boyutlarında artma saptanmayan hasta endokrinoloji polikliniğinde takibe alınmış. Hasta vücut kitle indeksi (VKi) değerlendirmesine göre $\left(27,3 \mathrm{~kg} / \mathrm{m}^{2}\right)$ kilolu idi. Gebeliği döneminde mide bulantıları nedeniyle kötü beslendiği; diyetle kalsiyum alımının yeterli olmadığı tespit edildi. Gebelik öncesinde de uzun dönemde düşük kalsiyum alımı mevcuttu. Gebeliği sırasında vitamin ve demir preparatları dışında ilaç kullanmayan hastanın doğum sonrası ağrısı sebebiyle bebeğini 1,5 ay emzirebildiği, doğumdan 6,5 ay sonra ilk adetini gördüğü öğrenildi. Hastanın soygeçmiş sorgulamasında bir özellik yoktu.

Fizik muayenesinde genel durumu iyi, bilinci açık, koopere idi. Sistemik muayenesinde patolojik bulgu saptanmadı. Torakal bölgede kifoplasti skar izi mevcuttu. Torakal kifozda hafif artma, lomber lordozda azalma, torakalde hafif düzeyde açıklığı sola bakan skolyoz, torakal ve lomber spinal çıkıntılarda hassasiyet, torakal ve lomber bölgede paravertebral kas spazmı ve hassasiyet mevcuttu. Gövde hareketlerinde tüm yönlerde ağrı ve kısıtlııı varken diğer eklem hareket açıklıkları tamdı. Bilateral üst ve alt ekstremite motor ve duyu muayenesinde anormallik saptanmadı. Derin tendon refleksleri normoaktifti ve patolojik refleks alınmadı.

Hastadan FTR servisinde yatışı sırasında tam kan sayımı, rutin biyokimya, sedimentasyon, CRP, Brucella aglütinasyon testi, parathormon (PTH), 25-OH D vitamini, idrarda kalsiyum atıımı, idrarda pyrilinks-D, osteokalsin, serum CTX, kortizol, protein elektroforezi, tiroid fonksiyon testleri istendi. Hafif alkalen fosfataz yüksekliği (311 U/L, Normal değer aralığı=0-270 U/L) ve $25-\mathrm{OH}$ vitamin $\mathrm{D}$ yetersizliği $(21 \mathrm{ng} / \mathrm{mL}$, Değer aralığı= >30ng/ml yeterli, 20-30 ng/ml yetersizlik), idrarda pyrilinks-D yüksekliği (13 nM/mMkreatinin, Normal değer aralığı=3-7,4nM/ mMkreatinin), 24 saatlik idrarda kalsiyum atıımında düşüklük (66mg/gün, Normal değer aralığı=100-300mg/gün), sınırda PTH yüksekliği $(67,7$ pg/mL, Normal değer aralığı=10-65pg/ $\mathrm{mL}$ ) dışında laboratuvar incelemelerinde anormallik saptanmadı. Tümör belirteçleri, meme ultrasonografisi ve mammografi, paratiroid sintigrafisinde patoloji saptanmadı.

Düz radyografilerde T8-T11 ve L2-L4 vertebraların ön kısmında kamalaşma mevcuttu. Torasik ve lomber vertebraların manyetik rezonans görüntüleme (MRG) tetkikinde T8'de kompresyon fraktürü, T11-12 ve lomber vertebralarda yaygın kamalaşma, T8, T11, T12 ve lomber vertebraların tamamında değişen derecelerde yükseklik kaybı ve korpuslarında ödematöz sinyal 
değişiklikleri saptandı (Resim 1). Çift-enerji x-ışın absorpsiyometri (DXA) yöntemi kullanılarak ölçülen kemik mineral yoğunluğu (KMY) (03. 2008) değerlendirmesinde L1-L4 Z-skoru -2,8, femur boyun Z-skoru -1,1 idi (Tablo 1).

Incelemeler sonucu multipl myelom ve kanser metastazı tanıları dışlandı. Kompresyonun sebebinin OP olduğu düşünüldü. Ikincil OP nedenleri dışlandıktan sonra hastaya GiO tanısı konuldu.

\section{Tedavi}

Hastanın ağrılı sırt bölgesine FTR servisinde yatışı sırasında 16 seans 20 dakika süreli hot pack ve elektroterapi tedavisi uygulandı. Hastaya ağrıları nedeniyle operasyondan sonra başlanmış olan gabapentin 1800 mg/gün 6 ay süreli kullandırıldı. Ekim 2012'den itibaren bir yıl süreyle pregabalin 300 mg/gün kullandı; ancak hasta bu tedavilerden az fayda gördü.

Kifoplasti operasyonundan itibaren antirezorptif/analjezik olarak nazal kalsitonin 200 IU/gün (bir yıl kullandı), 1200 mg kalsiyum/gün, 2000 IU vitamin D3/gün verildi. Analjezik olarak 8 ay süreyle tramadol $200 \mathrm{mg} /$ gün devam ettirildi. Hastanın FTR servisinde yatışı sonrası ağrıları giderek geriledi ve hasta diğer ilaç tedavilerine alendronat $70 \mathrm{mg} /$ hafta eklenerek taburcu edildi. Hastaya kalsiyum ağırıklı beslenme önerildi. Ek olarak omuz ve kalça bölgesi EHA, germe ve güçlendirme; sırt,

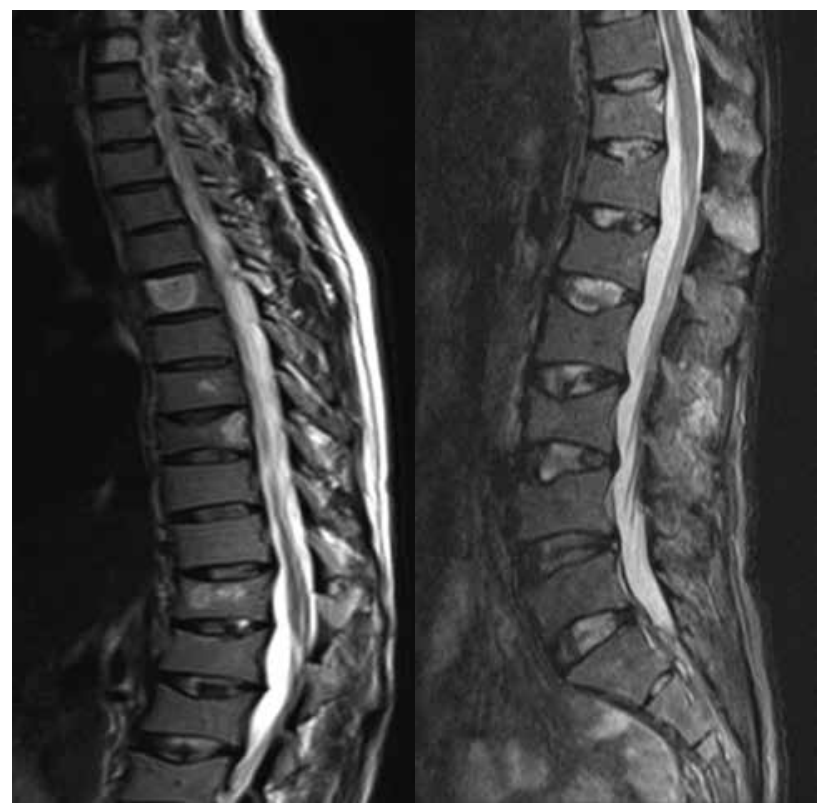

Resim 1. Hastanın preoperatif dönem torakal ve lomber manyetik rezonans görüntülemeleri görülmektedir

Tablo 1. Hastanın DXA (LUNAR) yöntemi ile yapılan kemik mineral yoğunluğu ölçümleri verilmektedir

\begin{tabular}{|l|l|l|l|l|}
\hline \multirow{2}{*}{$\begin{array}{l}\text { KMY ölçüm } \\
\text { tarihi }\end{array}$} & \multicolumn{2}{l|}{ DXA (L1-L4) } & \multicolumn{2}{l|}{ DXA (Femur boyun) } \\
\cline { 2 - 5 } & T-skoru & Z-skoru & T-skoru & Z-skoru \\
\hline 03.2008 & $-2,8$ & $-2,8$ & $-1,2$ & $-1,1$ \\
\hline 01.2009 & $-2,4$ & $-2,4$ & $-0,2$ & $-0,1$ \\
\hline 05.2011 & $-1,2$ & $-1,2$ & $-0,7$ & $-0,6$ \\
\hline 04.2012 & $-1,0$ & $-1,0$ & $-0,3$ & $-0,1$ \\
\hline
\end{tabular}

bel ekstansörleri germe ve güçlendirme, izometrik abdominal kaslarını güçlendirme egzersizlerini içeren ev egzersiz programı ve haftada 3 kez 45 dakika süreli yürüme verildi. Hastanın azalmış olan ağıısı 2-3 ay sonra tekrar başladı.

Beş yıl takip boyunca hasta hep aynı bölgede (sağ T8-T9 hizasında interskapular alanda) az da olsa ağrı (Görsel analog skalaya (GAS) göre ağrı skoru 3) tanımladı; ara ara ağrısının şiddetlendiği dönemler oldu. Ağrılı bölgeye yapılan lokal anestezik enjeksiyonlarından kısmen fayda gördü. Aralık 2011 'de ağrılı bölgeye 6 seans kuru iğneleme tedavisi uygulandı (GAS skoru 9'dan 4'e geriledi; iyilik hali 6 ay sürdü). Birer yıl arayla 3 kez yatarak tedavi verildi; hasta yapılan fizik tedavi modaliteleri ile artan ağrısında azalma belirtti. Hasta alendronat tedavisine 2 yıl devam etti. Hastaya idame tedavisi olarak 1200 mg kalsiyum/gün ve 800 IU vitamin D3/gün kullanması, önceden verilen ev egzersiz programına ve yürüyüşe devam etmesi önerildi.

Çekilen kontrol grafileri ve MRG'lerinde ek kırık gözlenmedi; ikinci bir operasyon uygulanmadı. Hastanın yakınmalarındaki gerilemeye paralel olarak KMY değerlerinde düzelme gözlendi (Tablo 1). Hastanın ağrısından dolayı olumsuz yönde etkilenen aile ve sosyal hayatı son 3 yıldır uygulanan tedavilerle büyük ölçüde düzeldi.

\section{Tartışma}

Literatürde GiO'ya neden olabilecek farklı risk faktörleri öne sürülmüştür. Bazı kadınların neden GiO gelişmesine yatkınlıkları olduğu tam anlaşılamamıştır. GiO tanısı alan kadınların ailesinde postmenopozal OP öyküsü saptanması üzerine herediter faktörlerin etkili olabileceği düşünülmüştür (5). Burada bahsedilen hastada pozitif aile öyküsü saptanmamıştır.

Normal gebelikle ilişkili değişiklikler kalsiyumun fetüse geçmesine izin verir. Annenin kalsiyum rezervinin \%7'si özellikle gebeliğin son üç ayında ve 6 aylık emzirme döneminde bebeğe transfer olur (6). Buradan da anlaşılacağı üzere fetüs, bir bakıma "kalsiyum hırsızı" olarak görev yapmaktadır. Birçok gebe ve emziren kadının günlük ihtiyacı olan kalsiyum (1000-1300 mg) ve D vitamini (600-800 IU) diyetle karşılanamamaktadır. Sonuç olarak; gebelik ve laktasyon süresince kemiklerden devam edecek olan bu mineral transferi iskelette belirgin rezorpsiyona yol açar. Bu kemik kaybı vertebral kemiklerde daha belirgindir. Mekanizması net olarak bilinmemekle beraber kemik kaybının emzirmeyi sonlandırdıktan sonra 6-12 ayda normale döndüğü gözlenmiştir $(3,7)$. Gebelik ve laktasyon döneminde hatta gebelik öncesinde yeterli kalsiyumdan zengin diyet almamış olmak da önemlidir. Hastamızda gebeliğin son 3 ayında ve erken postpartum dönemde yeterli kalsiyum alamamış olmanın, gecikmiş menarş gibi faktörlerinde GiO zeminini hazırlamış olabileceği düşünülmektedir. Gebelik sonrası menstrual döngüsü erken başlayan kadınlarda laktasyon boyunca toplam mineral kaybının daha az olduğu ve emzirmenin sonlandırıması ile KMY değerlerinin önceki değerlerine daha hızlı döndüğünü belirten çalışmalar vardır (8). Ancak laktasyon döneminin 
uzaması ile kemik dansitesinde iyileşme süreci arasında farklılık gözlenmediğini ileri süren araştırmalar da mevcuttur (9). Bu vakanın ilk menstrüel siklusu doğumdan 6,5 ay sonra olduğu için bu durumun tedaviye yanıtı hızlandırdığını düşünmekteyiz. Çalışmalarda GiO tanısıyla takip edilen hastalarda tespit edilen vertebral kırık miktarı 1, 4, 6 olarak değişmektedir $(10,11)$. Bu vakada ise değişen derecelerde 10 vertebra kırığı mevcuttu; bu durum hastalığın ciddiyetini göstermektedir. Literatürde GiO tanılı hastalarda spinal KMY'nin femoral KMY'den daha düşük olduğu gözlenmektedir (11). Çalışmalarda GiO tanıı hastaların ortalama t-skorları lomber bölgede -2,8 ile -3,3 arasında, femoral bölgede ise $-1,9$ ile $-2,4$ arasında değişmektedir $(10,11)$. Sekiz vertebra kırığı olan bir vakada ise lomber t-skoru $-4,7$, femoral t-skoru -3,1 olarak belirtilmiştir. Benzer şekilde bu vakada ise hastanın ilk başvurusundaki KMY'sinde L1-L4 t-skoru -2,8, Z-skoru -2,8, femur boyun t-skoru -1,2, Z-skoru -1,1 idi. Gebelik ilişkili OP'nin klinik özellikleri OP'nin diğer tiplerine benzerdir. En sık görülen semptomu ciddi sırt ve/veya bel ağrısıdır (11). Bazı hastalarda sırt ağrısı aylar içinde kendiliğinden düzelebilir, bazılarında ise bu süre uzayabilir ve ciddi sırt ağrısı şeklinde devam edebilir. Bizim olgumuzda ağrı torakal bölgede ve ciddi düzeyde idi. Sırt ağrısı bebeğini emzirmesini, günlük hayata ve sosyal yaşama katılımını önemli derecede kısıtlamıştı. Başlangıçtaki sırt ağrısının GAS skoru üzerinden 10 iken uygulanan cerrahi, fizik tedavi ve ilaç tedavisi ile sekizinci ayda 4'e indi. Beş yıllık takip süresince hastanın sadece operasyon bölgesinde (T8-9 sağ paravertebral hizasında) ara ara artan ağrıları oldu, hastanın yakın zamandaki sırt ağrısının GAS değeri 3 idi. Bu dönem içinde ağrısında artma olduğunda oral ve lokal analjezik, kuru iğneleme tedavileri uygulandı ve hasta bu tedavilerden fayda gördü.

Literatürde sunulan sınırlı sayıdaki olgulardan dolayı GiO’da etkili tedavi açısından görüşler çelişkilidir. Omurga KMY'sinde spontan düzelme sorunsuz gebeliklerin laktasyon döneminden sonra ve ilaç tedavisi uygulanmayan GiO'lu hastalarda \%6-\%8 olarak bildirilmiştir. Ilaç tedavisi verilen hastalarda ise 1-4 yıl sonrasında lomber KMY'de düzelme \%8 ile \%31 arasında değişmektedir (12). Bifosfonat ile antirezoptif tedavinin etkili ve hızı düzelme sağladığını bildiren olgular mevcuttur (13). O'Sullivian ve ark. yaptıkları çalışmada GiO tanılı 9 hastaya 24 ay süreli bifosfonat tedavisi uyguladıklarında spinal kemik dansitesinde \%23'lük artış tespit etmişlerdir (10). Başka bir çalışmada kemik dansitesindeki iyileşmenin postpartum dönemde ilk 12-18 aylarda daha belirgin olduğu ve çoğu hastanın normal aralığa ulaşamadığı bildirilmiştir. İyileşme sürecinin 2-4 yıla kadar uzayabildiğini gösteren çalışmalar da mevcuttur (9). Bizim olgumuzda ise 2 yıl uygulanan antiresorptif tedavi sonucunda spinal kemik yoğunluğunda \%52'lik artış gözlenmiştir.

Antiresorptif ilaçlar OP tedavisinde ilk seçenek ilaç olarak kullanılmaktadır (1). Çocuklarda da kullanılmakla birlikte uzun dönem etkileri tam olarak bilinmemektedir (11). Çalışmalarda premenopozal kadınlarda uzun dönem takipte iyi tolere edildiği ve etkili olduğu saptanmıştır. Olgumuzda da tedaviye nazal kalsitonin, alendronat, kalsiyum ve vitamin D3 kombinasyonu ile başlanmış; uygulanan tedaviler ile KMY değerlerinde düzelme gözlenmiştir.

Teriparatid, osteoporozda kemik oluşumunu sağlayan ve kırık riskini azaltan diğer bir tedavi seçeneğidir (14). Teriparatid tedavisi yüksek kırık riskli veya diğer OP tedavilerini tolere edemeyen ya da diğer OP tedavilerinden fayda görmeyen postmenopozal OP tanılı hastalarda kullanılabilir (11). Premenopozal dönemde teriparatid tercih nedenleri arasında hastanın yeniden gebelik istemesi, teriparatidin bifosfonatlar gibi yıllarca kemik matriksinde depolanmaması, bifosfonatların uzun dönemde prenatal etkilerinin bilinmemesi sayılabilir. Literatürde 32 yaşındaki multipl kırıklı, antikoagulan tedavisi nedeniyle ikincil OP düşünülen GiO tanılı bir hastaya teriparatid uygulanmış, ek olarak ağı tedavisi ve fizyoterapi verilmiştir. Altı ay sonraki kontrol KMY'sinde lomber t-skorunda başlangıca göre \%42'lik artış ve ağrıda azalma tespit edilmiş; yeni kırık gözlenmemiştir (1).

Akut kırıkların tedavisinde kifoplasti, vertebroplasti gibi perkutan yaklaşımlar ağrıyı azaltma yönünden oldukça etkilidir. MRG iyileşmekte olan kırıkları akut ve subakut kırıklardan ayırmada, hangi hastanın kifoplastiden fayda göreceğini göstermede yardıma olur (3). Bayram ve ark. sundukları spinal vertebral kırıkları olan 37 yaşındaki GiO tanılı olguda medikal tedavi ile birlikte kifoplasti uygulamış; hastanın ağrısında gerileme olduğunu bildirmişlerdir. Ancak kifoplastiden 2 ay sonra yeni kırık tespit ettiklerini rapor etmişlerdir. Bizim olgumuzda ağrının azalmasının yanı sıra 5 yıllık takip sürecinde yeni kırık oluşumu gözlenmemiştir (15) (Resim 2).

Sonuç olarak; gebelik veya laktasyon dönemindeki bir kadında sırt ve/veya bel ağrısı mevcutsa ayırıcı tanılar arasında GiO olabileceğini unutmamalıyız. Bu nadir OP tipi sebep olduğu kırıklarla, hastamızda olduğu gibi fonksiyonel kayıplara, günlük

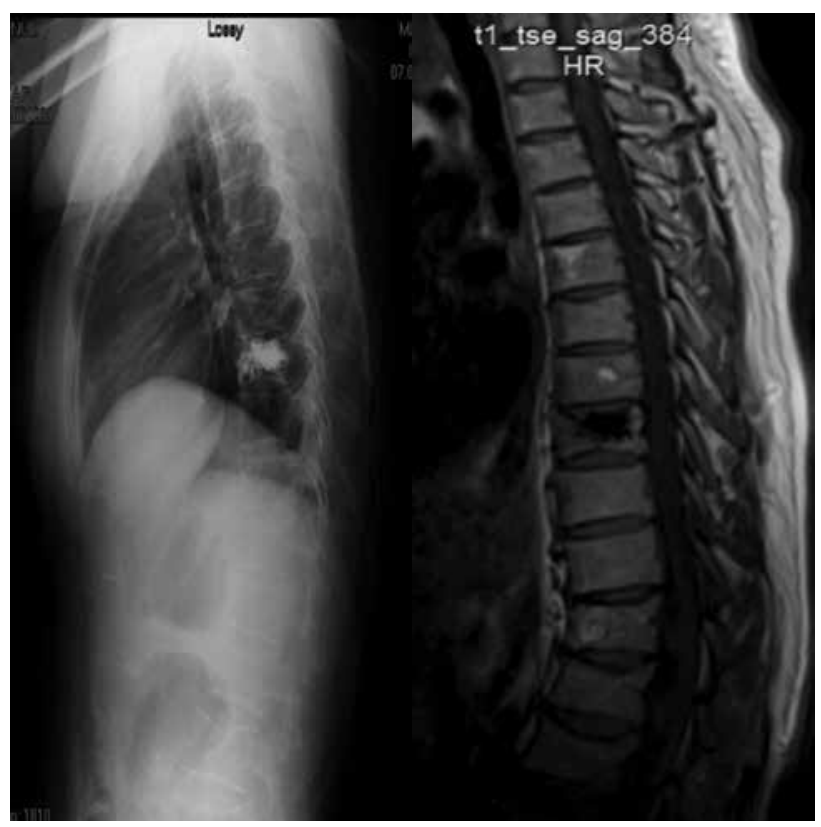

Resim 2. Hastanın 5. yıl kontrolünde çekilen torakal düz grafisi ve manyetik rezonans görüntülemesi görülmektedir 
yaşam aktivitelerinde kısıtlılığa ve ileri dönemlerde özürlülüğe neden olabilmekte ve anne-bebek ilişkisini, bebek emzirme dönemini olumsuz etkilemektedir. Dolayısıyla GiO tanısı erken zamanda konulmalı ve hastaya özgü bir tedavi programı yapılmalıdır.

\section{Kaynaklar}

1. Stumpf UC, Kurth AA, Windolf J, Fassbender WJ. Pregnancyassociated osteoporosis: an underestimated and underdiagnosed severe disease. A review of two cases in short- and long-term follow-up. Advances in Medical Sciences 2007;52:94-7.

2. Promislow J.H.E., Hertz-Picciotto I, Schramm M, Watt-Morse $\mathrm{M}$, Anderson J.J.B. Bed rest and other determinants of bone loss during pregnancy. American Journal of Obstetrics and Gynecology 2004;191:1077-83.

3. Akyüz G, Bayındır Ö. Gebelik ile ilişkili osteoporoz. Derleme. Türk Fiz Tip Rehab Derg 2013;59:145-50.

4. Sweeney AT, Blake M, Holick MF. Transient osteoporosis of hip in pregnancy. J Clin Densitom 2000;3:291-7.

5. Dunne F, Walters B, Marshall T, Heath DA. Pregnancy associated osteoporosis. Clin Endocrinol 1993;39:487-90.

6. Eisman J. Relevance of pregnancy and lactation to osteoporosis? Lancet 1998;352:504-5.
7. Davey MR, De Villiers JT, Lipschitz S, Pettifor JM. Pregnancy and lactation associated osteoporosis. JEMDSA 2012;17(3):149-53.

8. Kalkwarf HJ, Specker BL. Bone mineral changes during pregnancy and lactation. Endocrine 2002;17:49-53.

9. Phillips AJ, Ostlere SJ, Smith R. Pregnancy-associated osteoporosis: does skeleton recover? Osteoporosis Int 2000;1:449-54.

10. O'Sullivian SM, Grey AB, Singh R, Reid IR. Biphosphonates in pregnancy and lactation-associated osteoporosis. Osteoporos Int 2006;17:1008-12

11. Ofluoğlu O, Ofluoğlu D. A case report: pregnancy-induced severe osteoporosis with eight vertebral fractures. Rheumatol Int 2008;29:197-201

12. Di Gregorio S, Danilowicz K, Rubin M, Mautalen C. Osteoporosis with vertebral fractures associated with pregnancy and lactation. Nutrition 2000;16:1052-5.

13. Hellneyer L, Kuhnert M, Ziller V, Hadji P. The use of i.v. biphosphonate in pregnancy-associated osteoporosis-case study. Exp Clin Endocrinol Diabetes 2007;115(2):139-42.

14. Neer RM, Arnaud CD, Zanchetta JR ve ark. Effecet of parathyroid hormone on fractures and bone mineral density in postmenopausal women with osteoporosis. N Engl Med 2001;344:1434-41.

15. Bayram S, Ozturk C, Sivrioğlu K, Aydinli U, Kuçukoglu S. Kyphoplasty for pregnancy-associated osteoporotic vertebral fractures. Joint bone spine 2006;73(5):564-6. 